\title{
Analysis on the Marketing Strategy of Chanel
}

\author{
Wang Zihan \\ The Second High School attached to Beijing Normal University, Beijing, China \\ Author's Email: wangzihanjanice@163.com
}

\begin{abstract}
Chanel is an independent brand in the luxury industry. The main purpose of this article is to analyze the whole supplier audience and the industry environment. The result shows that the exquisite design concept is throughout all of the products. Chanel's market scope is gradually expanding. In addition to the affluent class that was originally targeted, the market of Chanel has gradually penetrated the performance of low and medium consumption level. It is no longer out of reach for most young people.
\end{abstract}

Keywords: Luxury Industry, Coco Chanel, Supplier Audience, Industry Environment

\section{INTRODUCTION}

Coco Chanel was born Gabrielle Bonheur Chanel on August 19, 1883, in Saumur, France. Her early years were anything but glamorous. At age 12, after her mother's death, Chanel was put in an orphanage by her father, who worked as a peddler. Chanel was raised by nuns who taught her how to sew a skill that would lead to her life's work. Her nickname came from another occupation entirely. During her brief career as a singer, Chanel performed in clubs in Vichy and Moulins where she was called "Coco." It is said that the name comes from one of the songs she used to sing, and Chanel herself said that it was a "shortened version of cocotte, the French word for 'kept woman,"' according to an article in The Atlantic."[1] This article is to do market research on Chanel, which is a unique brand in the luxury industry.

\section{BACKGROUND}

\subsection{Sales Volume}

Earlier, as, an old fashion house, Chanel published its annual sales report for 2019, with sales of nearly $\$ 12.3$ billion. Chanel maintained strong growth in the first year after the death of Lord Buddha. Asia became its most profitable market for the second year in a row, an increase of $10 \%$ compared with 11.1 billion in 2018. Although the group did not disclose the sales of individual items, the list of clothing and handbags designed by creative director Virginia Viard was the best, with sales increasing by $28 \%[3]$.

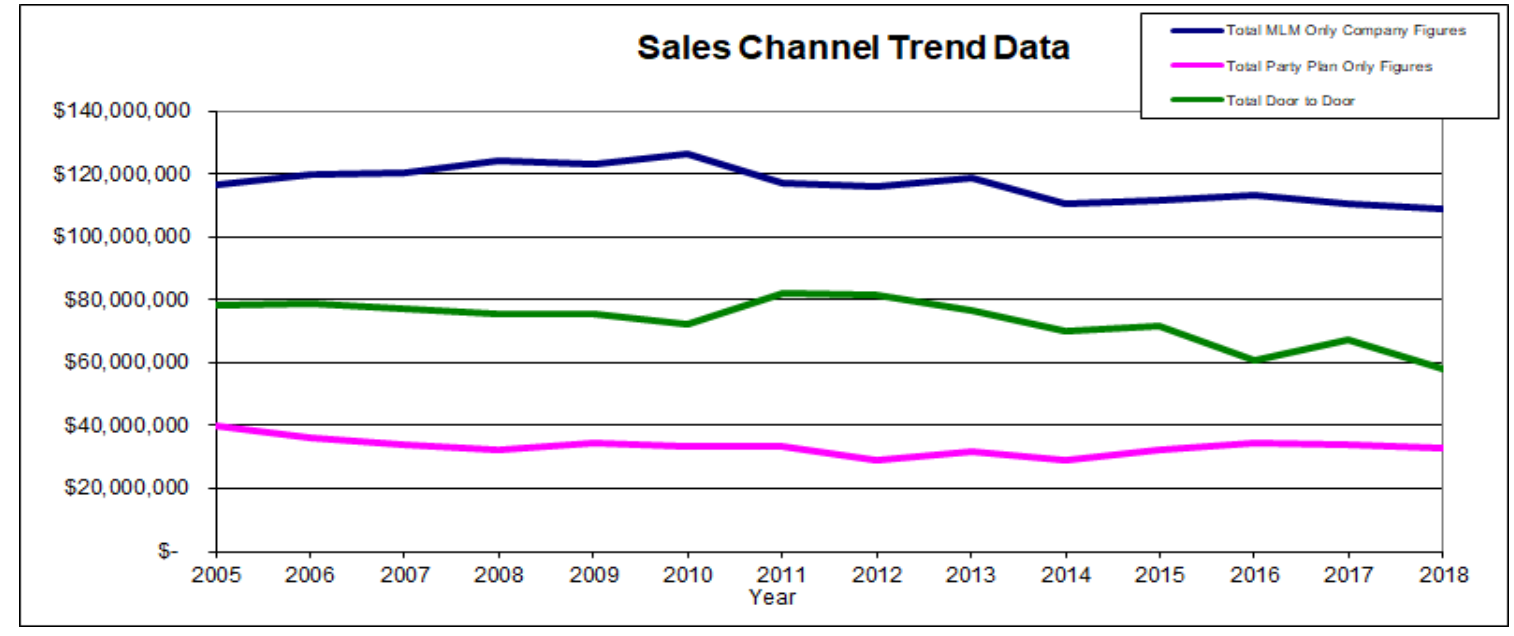

Figure 1 Sales Channel Trend Data[2] 
Chanel also warned that sales would drop sharply by 2020, mainly because the epidemic forced the closure of physical stores, as well as the change and decrease of consumer demand. In addition, Chanel did not have mature the development of e-commerce platform, which made the brand face an unprecedented crisis. From the trend data, we can clearly understand that sales value has stable growth. Chanel is affected by the new crown in 2020, which leads to the decline in sales of the whole brand. Chanel has always maintained an independent style. For example, Kering and LVMH both intend to annex Chanel, but Chanel has not published any financial reports in 108 years, which makes people curious. However, Chanel's chief financial officer, Philippe, is still a unique brand Blondiaux said the company's current financial position is very sound and has all the means to remain independent. "This financial statement shows that our financial position is very sound and we can maintain our position as a private, independent company for centuries to come." That's what Blondiaux said[3].

\subsection{Brand}

Chanel distributes its products through many channels, such as exclusive stores, e-commerce websites, multi-brand stores and high-end supermarkets, so that the products are sold worldwide. There are more than 300 Chanel boutiques in the world. With the increasingly demanding consumer demand, the old bottle and consumers do not support the increasing consumption standards, so it is necessary to upgrade Chanel 5 perfume again in bottle shape, making it completely independent of other high-end perfume.

Mrs. Chanel transformed the perfume bottle into a style similar to minimalism, forming a new fashion force, and this minimalist design touched the elegant atrium of ladies and gentlemen.

For Chanel's reform, the most important link is its control of advertising. Chanel often brings unforgettable memories to the viewers with the visual effect of impact, and also conveys a noble, fantastic and inviolable look. Chanel has extremely strict control over the media of advertising, which must be closely related to the target consumer groups of Chanel, such as fashion magazines, high-end hotels or clubs, etc. In terms of the number and cycle of advertising, Chanel is targeted and planned, and their advertising requires precision rather than wide coverage.

\section{ANALYSIS}

\subsection{Product}

There are tailored suits, women's wear, advanced garments, perfume, make-up, skincare products, footwear, handbags, glasses, watches, jewelry accessories, leather bags, etc. Chanel products also position different product series for different groups of people, and these products are also determined according to Chanel marketing strategy. In 1921, Ms. CHANEL and the famous perfume master Ernest Beaux, launched the world's most popular designer perfume: CHANEL N ${ }^{\circ} 5$ perfume, up to now CHANEL $\mathrm{N}^{\circ} 5$ is still the world's first selling perfume. Marilyn Monroe's quote "I only wear $\mathrm{N}^{\circ} 5$ to sleep" became the immortal legend of CHANEL $\mathrm{N}^{\circ}$ 5. The logo of "double C" has also made this bottle of perfume the most profitable product in Chanel's history.[4]

So far, Chanel's official website is still the focus of recommended products. Chanel rarely produces men's products. But as time goes on, Chanel has launched a series of blue perfume, but men's clothing is missing because of women's desire to be independent of men. Until now, Chanel's perfume and make-up are also well known worldwide. Now Chanel has launched the BRIC series, the most advanced series of Chanel make-up. Rarely seen high-end advertising on TV or in the street. But it can be seen in magazines in private clubs or firstclass cabin, which shows that their products and advertisements are matched by lean. Targeting consumers rather than advertising widely.

Chanel has created a surprising success in the field of cosmetics and perfume, Chanel products can always meet the needs of users, in line with the noble and simple style, conquered women, and made women's status improved to a certain extent. Chanel's service is also very good in boutiques or cosmetics shop. Staff will ask your passionate demand and then arrange recommended products according to your requirements and then carefully check the production date and expiry date to ensure that the products are in good condition. Chanel's main consumer groups are positioned as middle and senior class people. Most of them have strong consumption ability. As for the top class, Chanel has private customization or limited edition. For each product audience, Chanel has a clear and accurate planning. For example, the color makeup is more inclined to the lower middle class and the upper middle class In the color make-up, there are also BRICs series, which are luxury cosmetics for high-end customers.

\subsection{Price}

The price of Chanel is also different, like the watches and jewelry bags or clothes in the boutique, the price is around thousands of pieces, the basic ones are around tens of thousands of pieces, while the more expensive ones are customized or limited edition ones are over hundreds of thousands or hundreds of thousands.

Chanel's cosmetics and skincare products are cheap. Chanel usually doesn't have a discount all the year round. On websites or in a big store like Lane Crawford, we might have a discount sometimes. Chanel counters do not 
support any installment payment but with the development of mobile payment and we can try to use Alipay loans pay. Chanel's pricing has always been very mysterious. Chanel and Dior Louis Vuitton belong to the same first-line brands. In addition to the uneven prices of boutiques is generally between $10000 ¥$ and $100000 ¥$. Cosmetics shops mainly rely on sales to make huge profits. The price positioning is relatively reasonable, and there is little difference with the same level of brand price.[5] In the last century, Chanel has established its own brand. In addition to the above reasons, there are some other reasons for Chanel's audience, such as Hollywood stars or world-class rich people, because they don't care about the price of the product. What they care about is the unique design of the product.

\subsection{Distribution}

Chanel does not have any agents and wholesalers. All the Chanel products that can be bought are available in the counter or online or offline stores, while cosmetics are sold separately in cosmetics stores. Sales channels and distribution, for example, in boutiques, are only available in relatively luxurious store fields. For example, in Beijing, only SKP and International Trade stores have sales channels, while cosmetics stores target consumer groups that are not as basic as boutiques and can be found in slightly larger mall. Worldwide, Chanel's user groups are mainly celebrities or royal nobles. Chanel boutiques can also be seen at airports in New York, Boston, Amsterdam, Sao Paulo, Sydney, Hamburg, Cannes, Miami, Bangkok, Geneva, Tokyo, Saint Tropez, Moscow, Los Angeles, Paris, Dubai and London Boutiques. They are located in the most luxurious and most famous shops in the locality. Chanel has a total of about 310 boutiques, 128 in North America, 94 in Asia, and 70 in Europe. The rest is perfume and make-up, which are located in various high-end stores[6].

\subsection{Marketing}

They are reluctant to put the advertisement in the public. But in recent years, it has changed. Nell will choose some Hollywood stars or supermodels to speak for them and shape their brand influence through their influence. When stars wear custom-made high-end gifts and hold beautiful bags when they are at the awards ceremony or walking on the red carpet, the media and news critics will focus on the stars. The relationship between brands and stars just like a secret agreement, both of them can benefit greatly from it. The shooting method of Chanel's advertisement is in a traditional style. What Chanel occupies in fashion is the dominant position of women's clothing. Until today, Chanel's women's clothing is also unique in the world. With the rise of digital advertising, even the traditional Chanel has joined in the publicity. In order to further improve the brand awareness, Chanel also opened a fashion show week to show Chanel's noble and simple style. At the same time, they also invited some high-end customers to watch and order clothes. This sales process can not help but be admired. Sometimes, they will choose to hold art touring exhibitions to promote worldwide, starting from April 2012 in Tokyo by December 2013, in Singapore and other 16 major cities, such as New York, Paris, Shanghai, Dubay and Moscow.

\subsection{Consumer Emotion}

Chanel's marketing gives people a sense of quick and effective introduction. Their high requirements for advertising and the accuracy of their advertising are unique in the whole luxury jewelry brand. Their advertising and influence can be accurately put into the right consumers anytime and anywhere, instead of the paved advertising like Louis Vuitton.

Chanel's promotion is aimed at the necessity of consumers, which is undoubtedly more efficient and rapid than the wasteful mindless advertising. But with the rise of digital media, Chanel has also shifted its attention to it, and Chanel's advertising is as simple and effective as founder Gabrielle Bonheur Chanel. Chanel did not speculate too much on consumer psychology, but focused on the product itself, constantly innovating style and improving quality, so as to make the brand more famous. In this era of capital rampant, this brand with craftsman's heart is precious. It is the spirit of Chanel brand to create an eternal style and avant-garde and exquisite design that has moved so many consumers.

\section{COMPARISON BETWEEN DIOR AND CHANNEL}

Dior and Chanel are the same first-line brands, but compared with Chanel, Dior's performance in 2020 is particularly prominent. Now Dior is subordinate to the Louis Vuitton group. With the influence of renowned stars, the cross-border alliance of sports brands and luxury goods has been greatly expanded. Moreover, Dior's turnover is ahead of Chanel's products compared with Chanel Dior's products, cosmetics, watches, perfume, jewelry, men's wear, high fashion and private custom.

\section{CONCLUSION}

Chanel always adheres to the unique personality and style, and has the courage to innovate and maintain the influence of the brand. At the same time, Chanel's promotions are also diverse, mainly focusing on film and television advertising, newspaper advertising, online publicity, window advertising, outdoor advertising as the center. Moreover, Chanel's sales area and location are also selected as large cities, high-end shopping malls and exclusive stores. The famous Chanel 5 perfume is also the love of Queen Marilyn Monro. Marilyn Monro once said in an interview: "I sleep only in Chanel 5." This 
greatly improved Chanel's influence and popularity, so far, Chanel No. 5 still exudes charming light. Chanel's famous logo to double $\mathrm{C}$ and camellia, are a unique style, with elegant, simple charm. Chanel's products range from clothing, leather goods, watches, jewelry, shoes and maintenance products. Most of the price is at the top of the pyramid, but it still does not reduce the number of consumers. This is the light of Chanel. It is no longer out of reach for most young people. This is also because the market of Chanel has gradually penetrated the performance of low and medium consumption level.

\section{AUTHORS' CONTRIBUTIONS}

In the whole process, the author herself collects, organizes, thinks, revises and finally completes this article.

\section{ACKNOWLEDGMENT}

I would like to give my sincere gratitude to the teachers' help. This paper is finally completed with their extraordinary patience and consistent encouragement.

\section{REFERENCES}

[1] Coco Chanel. Biography. FEB 27, 2020. https://www.biography.com/fashion-designer/cocochanel

[2] Sales Channel Trend Data. Bing. 2020.

http://www.dsanz.co.nz/statistics/graphs/chanel/Sales_c hanel_Trends_by_Valu.gif

[3] LAUREN SHERMAN. Chanel Surpasses \$11 Billion in Sales, Dismisses Rumours of Imminent Sale. Business of fashion.JUNE 17, 2019

[4] History of Chanel. Daxueconsulting. 2020. https://daxueconsulting.com/analysis-on-chanel-inchina/

[5] Chanel. 2020. https://www.chanel.com/us/

[6] Chanel Marketing Mix (4Ps) Strategy. Mbaskool.2020.

https://www.mbaskool.com/marketingmix/products/17280-chanel.html 